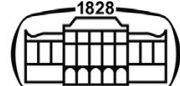

AKADÉMIAI KIADÓ

Interventional Medicine and Applied Science

11 (2019) 4, 213-215

DOl:

$10.1556 / 1646.2020 .00003$

(C) 2018 The Author(s)

\title{
Levels of glucagon-like peptide 1 in hyperemesis gravidarum
}

\section{AYLA AKTULAY ${ }^{1}$, Y ENGIN-USTUN ${ }^{1}$, O KAYMAK ${ }^{1}$, AYSE SEVAL OZGU-ERDINC ${ }^{1}$, CANAN DEMIRTAS ${ }^{2}$, MUSTAFA KARA $^{1 *} \odot$, NURI DANISMAN ${ }^{1}$ and SALIM ERKAYA ${ }^{1}$}

\author{
${ }^{1}$ Obstetrics and Gynecology Department, Zekai Tahir Burak Women Health Training and Research \\ Hospital, Ankara, Turkey \\ ${ }^{2}$ Biochemistry Department, Gazi University, Faculty of Medicine, Ankara, Turkey
}

Received: April 12, 2018 • Accepted: May 18, 2018

Published online: July 20, 2021

\begin{abstract}
Objective: Glucagon-like peptide 1 (GLP-1), a gut-derived peptide has been reported to have insulin-like effects. Our aim is to examine GLP1 levels in hyperemesis gravidarum (HEG). Materials-methods: The study population consisted of 2 groups: Group 1 (control subjects) consisted of 22 women with uncomplicated singleton pregnancies in the first trimester. Group 2 consisted of 22 singleton pregnancies complicated by HEG. Glucose and GLP1 levels were determined. Enzyme-linked Immunosorbent Assay Kit for Glucagon like Peptide 1 (GLP1) was used (Uscn, Life Science Inc.). Results: No significant differences in maternal age, gestational age and gravida were observed between hypermetric and control groups. Maternal serum GLP1 levels were significantly higher in HEG compared with control group $(P=0.004)$. Conclusion: The results of our study revealed that the presence of increased GLP1 levels in women with HEG could contribute to the pathogenesis of the disease. Our results indicated that increased GLP1 levels may be associated with hyperemesis gravidarum. The limitation of our study was the restricted number of patients. Large prospective and randomized studies are required to evaluate the effect of GLP1 levels on hyperemesis gravidarum.
\end{abstract}

\section{KEYWORDS}

hyperemesis gravidarum, glucagon-like peptide 1

\section{INTRODUCTION}

Characterized by severe nausea and vomiting due to pregnancy resulting in dehydration and electrolyte imbalance, metabolic disturbance and the need for hospitalization; approximately $0.3-2 \%$ of pregnancies display complications caused by hyperemesis gravidarum (HEG) [1].

The etiology of HEG is thought to be multi-factorial with biological, psychological and socioeconomic reasons, but it is still not clear. Studies on the etiologic biomarkers for HEG are increasing in number, which can be grouped in 3 pathoetiological notions: preexisting gastrointestinal disease, placental growth and function, and maternal endocrine function [2]. Several adipokines (vaspin, leptin, ghrelin, nesfatin) related to maternal endocrine function, were studied in HEG [3-7].

Glucagon-like peptide 1 (GLP-1) is a gut-derived peptide that has been reported to have insulin-like effects. Through a postprandial mechanism, GLP-1 is released from endocrine L-cells into the splanchnic and the portal circulation. By increasing the postprandial insulin release, decreasing glucagon secretion and delaying gastric emptying; GLP-1 lowers plasma glucose and improves insulin sensitivity [8]. The aim of this study is to examine GLP1 levels in HEG. 


\section{MATERIALS AND METHODS}

During a 3-month period; eligible women were consecutively recruited from outpatient clinics and obstetrics services of Zekai Tahir Burak Women Health and Training Hospital for this case-control study. Approval of the institutional review board and informed consent of all the patients involved were obtained.

Two groups were formed for the study population: Group 1 (control patients) consisted of 22 women with uncomplicated singleton pregnancies in the first trimester. Group 2 consisted of 22 singleton pregnancies which were complicated by HEG. The HEG definition criteria were determined as: (1) a weight loss of at least $2.25 \mathrm{~kg}$, (2) ketonuria $>80 \mathrm{mg} / \mathrm{dl}$ in a random urine specimen, (3) hyponatremia (sodium $<134 \mathrm{mEq} / \mathrm{dl}$ ) or hypokalemia (potassium $<3.0 \mathrm{mEq} / \mathrm{dl}$ ) requiring intravenous replacement, or (d) more than two visits to the Obstetric Emergency Department due to HEG. The presence of maternal diseases, smoking, drug abuse, alcohol abuse, history of obstetric complications during previous pregnancies, and usage of any pharmacological agents were accepted as the exclusion criteria. The patients in the control group were selected on a 1 to 1 ratio from among the routine antenatal clinic patients. The last menstrual period was used to calculate the gestational age and confirmed by routine ultrasonography at the $11^{\text {th }}-12^{\text {th }}$ weeks of gestation.

$5 \mathrm{ml}$ blood sample was obtained from each patient after an 8-h fasting period. Thyroid stimulating hormone (TSH), glucose and GLP1 levels were measured. Glucagon like Peptide 1 (GLP1) measurements were performed by Enzyme-linked Immunosorbent Assay Kit (Uscn, Life Science Inc.). fT3 and fT4 levels were determined by electrochemiluminescence immunoassay (ECLIA) on Roche autoanalyser (Roche Diagnostics GmbH, Mannheim, Germany) using commercial kits produced by Roche Diagnosis $(\mathrm{GmbH}$, Mannheim, Sandwich Elecsys). The minimum detectable level of human GLP1 is typically less than $4.81 \mathrm{pg} / \mathrm{mL}$. IntraAssay CV is $<10 \%$ and inter-Assay CV is $<12 \%$.

SPSS computer software (version 15.0, SPSS, Chicago, IL, USA) was used for all statistical analyses. The Kolmogorov Smirnov test was used for data distribution assessment. Means and standard deviations were calculated for normally distributed data, and those not parametrically distributed were shown as median. Unpaired $t$-test for independent samples or the Mann-Whitney $U$ test, where appropriate was used for comparisons of the groups for continuous variables. The strength of association between parametric variables was calculated using Pearson's correlation test and the Spearman Rho correlation test was used for non-parametric variables. $P<0.05$ was considered to be significant.

\section{RESULTS}

Baseline characteristics of the two groups are shown in Table 1. No significant differences in maternal age, gestational age and gravida were observed between hyperemesis and control groups. Serum TSH, fT3, and fT4 levels differed significantly between the groups (Fig. 1). Maternal serum GLP1 levels were significantly higher in hyperemesis gravidarum compared with control group $(P=0.004)$ (Fig. 2).

We found no correlation between GLP1 $(r=0.241$, $P=0.114)$ and age, GLP1 and TSH levels $(r=-0.151$, $P=0.351)$ and GLP1 and glucose $(r=0.088, P=0.61)$.

Table 1. Epidemiologic characteristics of the two groups

\begin{tabular}{lccc}
\hline & $\begin{array}{c}\text { Hyperemesis } \\
\text { gravidarum } \\
(n=22)\end{array}$ & $\begin{array}{c}\text { Control } \\
(n=22)\end{array}$ & $P$ \\
\hline $\begin{array}{c}\text { Maternal age } \\
\text { (Years) }\end{array}$ & $28.0 \pm 5.3$ & $25.0 \pm 6.6$ & 0.067 \\
$\begin{array}{c}\text { Gestational age } \\
\text { (Days) * }\end{array}$ & $55.9 \pm 11.9$ & $63.5 \pm 13.8$ & 0.068 \\
$\begin{array}{l}\text { Gravida** } \\
\text { Parity** }\end{array}$ & $2(0-6)$ & $1.5(1-5)$ & 0.195 \\
Glucose* $^{*}(\mathrm{mg} / \mathrm{dl})$ & $1(0-2)$ & $0(0-3)$ & 0.266 \\
\end{tabular}

*Values are mean \pm standard deviation.

**Values are median (minimum-maximum).

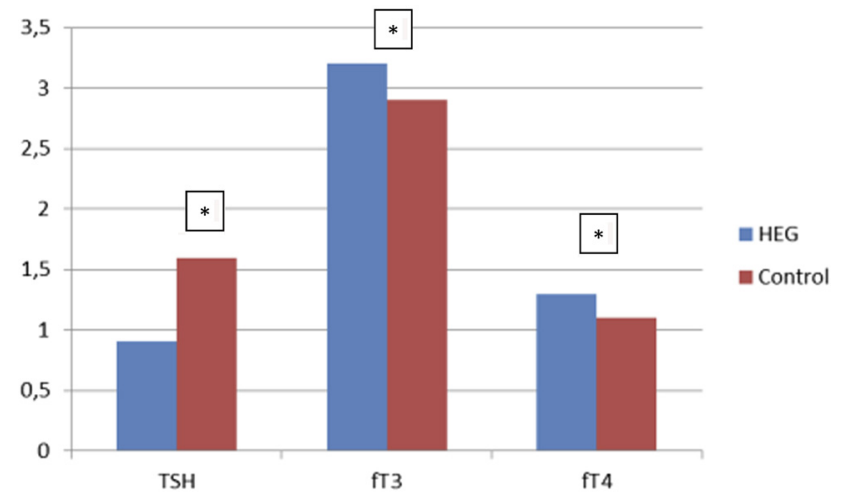

HEG hyperemesis gravidarum, TSH ( $\mu \mathrm{IU} / \mathrm{ml})$, fT3 $(\mathrm{pg} / \mathrm{mL}), \mathrm{fT} 4(\mathrm{pg} / \mathrm{mL})$. * statistically significant

Figure 1. Hormonal parameters of the two groups

\section{GLP 1}

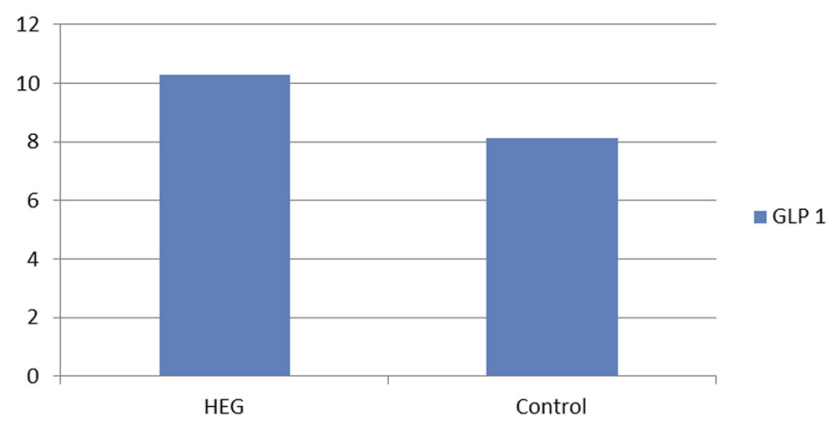

Figure 2. Distribution of GLP1 levels between the groups 


\section{DISCUSSION}

Several adipokines were studied in women with HEG [3-7]. Engin-Ustun et al. [3] found that women with HEG had significantly higher vaspin levels, compared to BMI-matched healthy controls. They also found that women with HEG had significantly higher levels of CRP than the control group. They advocated that the augmented serum vaspin concentration might be due to a diminished catabolism of vaspin by the liver, or another cause. Aka et al. [5] concluded that leptin could play a role in, and be defined as, a marker of hyperemesis gravidarum. Gungor et al. [7] revealed a possible role of leptin and nesfatin-1, which might be involved in the pathology of HEG.

GLP-1 is a hormone which is secreted from intestinal Lcells in response to nutritional stimuli. Anti-inflammatory and atheroprotective effects have been described for GLP-1 which extends to cardioprotection during acute myocardial infarction [9]. The impaired GLP-1 secretion has been reported in obese and diabetic subjects in some studies [10]. Fasting GLP1 levels were found to be increased significantly from the second to the third trimester [11]. The authors suggested a possible role of maternal GLP1 in mechanisms that compensate for the pregnancy-related increase in glycemia and insulin resistance, revealing a role of this peptide in maternal metabolism and weight [11].

We found significantly higher maternal serum GLP1 levels in HEG compared with control group supporting the role of GLP1 in maternal metabolism similar to the study of Valsamaki et al. [11]. On the other hand, similar to our results, Akdemir et al. [12] found that thyroid dysfunction was more common in HEG than in controls ( $38 \%$ vs. $6 \%$ ).

Funding sources: None declared.

Authors' contribution: Conception and design of study: Yaprak Engin-Ustun, Ayla Aktulay.

Acquisition of data: Ayşe Seval Ozgu Erdinc, Oktay Kaymak, Ayla Aktulay.

Analysis and interpretation of data: Canan Demirtas, Mustafa Kara, Nuri Danisman.

Reviewing the manuscript: Yaprak Engin-Ustun, Mustafa Kara, Salim Erkaya.

Conflicts of interest: The authors report no conflicts of interest. The authors alone are responsible for the content and writing of the paper. No commercial relationship existed in the form of financial support or personal financial interest.

\section{ACKNOWLEDGEMENT}

None declared.

\section{REFERENCES}

[1] Tan PC, Jacob R, Quek KF, Omar SZ. The fetal sex ratio and metabolic, biochemical, haematological and clinical indicators of severity of hyperemesis gravidarum. BJOG 2006; 113: 733-7.

[2] Niemeijer MN, Grooten IJ, Vos N, Bais JM, van der Post JA, Mol BW, et al. Diagnostic markers for hyperemesis gravidarum: a systematic review and metaanalysis. Am J Obstet Gynecol 2014; 211:150.e1-15.

[3] Engin-Ustun Y, Tonguç E, Var T, Deveer R, Yilmaz N, Danisman $\mathrm{N}$, et al. Vaspin and C-reactive protein levels in hyperemesis gravidarum. Eur Rev Med Pharmacol Sci 2013;17: $138-40$.

[4] Unsel N, Benian A, Erel CT. Leptin levels in women with hyperemesis gravidarum. Int J Gynaecol Obstet 2004;84:162-3.

[5] Aka N, Atalay S, Sayharman S, Kiliç D, Köse G, Küçüközkan T. Leptin and leptin receptor levels in pregnant women with hyperemesis gravidarum. Aust N Z J Obstet Gynaecol 2006;46: 274-7.

[6] Oruç AS, Mert I, Akturk M, Aslan E, Polat B, Buyukkagnıcı U, et al. Ghrelin and motilin levels in hyperemesis gravidarum. Arch Gynecol Obstet 2013;287:1087-92.

[7] Gungor S, Gurates B, Aydin S, Sahin I, Kavak SB, Kumru S, et al. Ghrelins, obestatin, nesfatin-1 and leptin levels in pregnant women with and without hyperemesis gravidarum. Clin Biochem 2013;46:828-30.

[8] Holst JJ. The physiology of glucagon-like peptide 1. Physiol Rev 2007;87:1409-39.

[9] Lehrke M, Marx N. Cardiovascular effects of incretin-based therapies. Rev Diabet Stud 2011;8:382-91.

[10] Ranganath LR, Beety JM, Morgan LM, Wright JW, Howland R, Marks V. Attenuated GLP-1 secretion in obesity: cause or consequence? Gut 1996;38:916-9.

[11] Valsamakis G, Margeli A, Vitoratos N, Boutsiadis A, Sakkas EG, Papadimitriou G, et al. The role of maternal gut hormones in normal pregnancy: fasting plasma active glucagon-like peptide 1 level is a negative predictor of fetal abdomen circumference and maternal weight change. Eur J Endocrinol 2010;162:897-903.

[12] Akdemir N, Bilir C. Thyroid dysfunction in hyperemesis gravidarum: a study in Turkish pregnant women. J Turk Ger Gynecol Assoc 2011;12:140-3. 